University of Wollongong

Research Online

Faculty of Social Sciences - Papers (Archive) Faculty of Arts, Social Sciences \& Humanities

2014

Socio-emotional connections: identity, belonging and learning in online interactions. A literature review

Janine Delahunty

University of Wollongong, jd40@uowmail.edu.au

Irina Verenikina

University of Wollongong, irina@uow.edu.au

Pauline Jones

University of Wollongong, paulinej@uow.edu.au

Follow this and additional works at: https://ro.uow.edu.au/sspapers

Part of the Education Commons, and the Social and Behavioral Sciences Commons

Research Online is the open access institutional repository for the University of Wollongong. For further information contact the UOW Library: research-pubs@uow.edu.au 


\title{
Socio-emotional connections: identity, belonging and learning in online interactions. A literature review
}

\begin{abstract}
This review focuses on three interconnected socio-emotional aspects of online learning: interaction, sense of community and identity formation. In the intangible social space of the virtual classroom, students come together to learn through dialogic, often asynchronous, exchanges. This creates distinctive learning environments where learning goals, interpersonal relationships and emotions are no less important because of their 'virtualness', and for which traditional face-to-face pedagogies are not neatly transferrable. The literature reveals consistent connections between interaction and sense of community. Yet identity, which plausibly and naturally emerges from any social interaction, is much less explored in online learning. While it is widely acknowledged that interaction increases the potential for knowledge-building, the literature indicates that this will be enhanced when opportunities encouraging students' emergent identities are embedded into the curriculum. To encourage informed teaching strategies this review seeks to raise awareness and stimulate further exploration into a currently underresearched facet of online learning.
\end{abstract}

\section{Keywords}

connections, identity, emotional, socio, belonging, review, learning, online, interactions, literature

\section{Disciplines}

Education | Social and Behavioral Sciences

\section{Publication Details}

Delahunty, J., Verenikina, I. \& Jones, P. (2014). Socio-emotional connections: identity, belonging and learning in online interactions. A literature review. Technology, Pedagogy and Education, 23 (2), 243-265. 


\title{
Socio-emotional connections: identity, belonging and learning in online interactions. A literature review
}

Janine Delahunty, Irina Verenikina, Pauline Jones

\begin{abstract}
This review focuses on three interconnected socio-emotional aspects of online learning: interaction, sense of community and identity formation. In the intangible social space of the virtual classroom students come together to learn through dialogic, often asynchronous, exchanges. This creates distinctive learning environments where learning goals, interpersonal relationships and emotions are no less important because of their 'virtualness', and for which traditional face-to-face pedagogies are not neatly transferrable. The literature reveals consistent connections between interaction and sense of community. Yet identity, which plausibly and naturally emerges from any social exchange, is much less explored in online learning. While it is widely acknowledged that interaction increases the potential for knowledge-building, the literature indicates that this will be enhanced when opportunities encouraging students' emergent identities are embedded into the curriculum. To encourage informed teaching strategies, with particular focus on higher education contexts, this review seeks to raise awareness and stimulate further exploration into a currently underresearched facet of online learning.
\end{abstract}

Keywords: identity; sense of community; interaction; online learning; asynchronous communication; higher education

\section{Introduction}

The recent era of virtual education has been ushered in by the rapid implementation of online learning options in higher education, with the potential to meet student demand for flexible study options as well as the promise of equity for those unable to attend oncampus classes (White, 2003; Kelly \& Stevens, 2009). In addition, many higher education providers worldwide have been wooed by the potential for cost-cutting and a larger share of an increasingly competitive market (Yelland \& Tsembas, 2008; Roberts \& Crittenden, 2009).

It could be argued that what has ostensibly been seen as a cost effective solution has been at the expense of research into appropriate pedagogies for this unique learning environment (Salmon, 2005; Hull \& Saxon, 2009). This is reflected in volumes of literature documenting issues faced by online providers and their students. Some of these concern student retention (Moody, 2004), student satisfaction (Swan, 2001; Stein, Wanstreet, Calvin, Overtoom \& Wheaton, 2005), challenges around development of critical thinking skills (Maurino, 2006; Garrison \& Arbaugh, 2007; Garrison \& Vaughan, 2008), beneficial levels of participation (Coffin, Painter \& Hewings, 2005; Exter, Korkmaz, Harlin \& Bichelmeyer, 2009; Tsai, 2011), and the effect of tutor involvement (Gilbert, Morley \& Rowley, 2007; Liu, Magjuka, Bonk \& Lee, 2007), to name a few. The news is not all grim however, with some reporting on strategies for reducing isolation (Ice, Curtis, Phillips \& Wells, 2007; Kelly \& Stevens, 2009), identifying how to harness asynchronous communications to develop deep learning and critical thinking skills (Arend, 2009; Richardson \& Ice, 2010), and exploiting the communication time-lag of discussion boards as a tool for second language 
development (Birch \& Volkov, 2007). Despite these encouraging indications, it is still consistently reported that a sense of isolation is more commonly experienced by distance learners than by on-campus students (White, 2003; Bartlett, 2008; Huijser, Kimmins \& Evans, 2008; Owens, Hardcastle \& Richardson, 2009; Kwon, Han, Bang \& Armstrong, 2010). The wider concerns emanating from this are implications for learners as individuals, for the learning group as a whole, and for the flow-on effect to the distance learning experience.

What is perhaps the key pedagogical issue is the physical and geographical separation of the student from their instructor and the institution (Hull \& Saxon, 2009), creating a greater potential for misunderstanding in what Moore (1993) described as the "psychological and communications space" (p. 22). This notion recognises the presence of socio-emotional factors in any activity involving relationships between diverse individuals (Gunawardena \& Zittle, 1997). While students and tutors must negotiate this 'space', how best to do this can be time-consuming for staff, who have other workload concerns to consider, such as quality of subject content, resources and administrative duties (Salmon, 2005; Kelly \& Stevens, 2009 ). Since Moore's first writings on distance education, technological advancements have dramatically changed the face of distance learning. What remains relatively unchanged though is the very real challenge to subject designers and educators of how to reduce the risk of misinterpretation and facilitate meaningful learning experiences that are not diminished by the mode of delivery (Garrison, 2011).

In terms of online pedagogy, rapidly changing technologies have outpaced research on how to appropriately address the intangible social space of the virtual classroom. These distinctive learning environments are often created through text-based communications, but despite their 'virtualness' they are no less socially or emotionally 'real' than face-to-face interactions. This requires a shift that focuses more on "pedagogical innovation" (Salmon, 2005, p. 205), as appropriate online pedagogic practices are not neatly transferrable from traditional approaches. The assumption being made here is that students require participation in dialogue to learn (Vygotsky, 1978; Alexander, 2008), regardless of whether learning in a virtual environment or in face-toface. A sociocultural approach to learning views interaction and the development of new understandings as intrinsically linked and as inseparable from the context (Vygotsky, 1978). The challenge then is to understand how online communication, disconnected from a physical presence, impacts on learning and how this social context may contribute to the sense of isolation felt by many more distance learners than by face-to-face students. The question of who these learners are also arises, and whether (or how) being able to communicate a sense of identity (or not) impacts the learning experience.

\section{Defining online 'participation' and 'interaction'}

At this point some clarification of what constitutes participation and interaction is necessary. The terms both suggest some kind of reciprocal action and are often used interchangeably in the literature, however there are some nuanced differences which might be amplified in the context of online learning.

In online contexts participation is commonly text-based and most often evidenced through written artefacts or 'posts' of the authors' ideas. However, while 'public' display of a post indicates participation, the level of meaningful interaction in 
which the person engages, might differ. Interaction, from a sociocultural perspective, refers to both the individual and collective transformation of knowledge occurring through dialogic exchanges between people (Vygotsky, 1978). It is through these kinds of social exchanges that individual learning is driven by the dialectic between individual and collective understandings (Mercer \& Howe, 2012). Thus, it is how individuals involve themselves in the conversation which defines their engagement in a meaningful dialogue, which is not unlike how it is determined in a face-to-face context. Interaction perhaps could even be considered as the online counterpart of tutorial discussion where there is a sense of cumulative understandings being developed through talking and listening.

Ascertaining the level of participation of those who 'lurk' is difficult even in face-to-face situations. It becomes even more so in asynchronous online environments where immediate and apparent contextual or behavioural cues do not exist, especially as participation is text-based. Thus in online discussion there may be a tendency towards utterances that are minimally dialogic, sometimes referred to as monologues (Garrison \& Cleveland-Innes, 2005) or as the "separate voice" (Rovai, 2002a, p. 8). This belies a complexity of participation as monologic contributions can be beneficial in coconstructing knowledge (and thus beneficial to the learning community) but are often perceived as non-conducive to community building. This may in part be due to dialogic processes being shut down or discouraged by monologic utterances as they tend not to invite discussion (Martin \& White, 2005). Open interaction can be hindered if monologic contributions are interpreted as a lack of willingness to interact, and can seem particularly so when sensitivity to the interpersonal is backgrounded by the 'facts' being put forward, such as in task-oriented contributions. This may be more indicative of a lack of skill in communicating in this mode, but could equally be positioning manoeuvres in expert/novice power relations. Despite this there may still be some sense of community being developed as a result of the contribution to cumulative knowledge. However, even though this may be participation per se, it is not the kind of online interaction that is encouraged for building a sense of community amongst learners, and

alludes to a complexity that warrants further discussion. Participation then can manifest as individualistic (even insular) behaviour and range to more inclusive behaviours, which display a value attached to sharing and collaboration for the benefit of the group (Rovai, 2002a). If dialogue, in which ideas are heard and jointly considered (Mercer \& Howe, 2012), is a defining characteristic of interaction, the kind of participation that is usually espoused in online learning is that which also involves dialogic interaction with others. Wenger's definition of participation is that it is "both personal and social" (1998, p. 56), and therefore involves the whole person, which comprises physical, cognitive and socio-emotional makeup. It is perhaps the absence of 'body' in online relations which foregrounds socio-emotional influences on participation.

\section{Socio-emotional aspects in online learning}

Socio-emotional factors in learning include personality, emotions, and values of socially participating individuals. Since being physically present is redundant in online learning, participation of the 'whole person', as Wenger (1998) argues, must be reconceptualised as dialogic exchanges involving the cognitive, the emotions, and interpersonal social relations. Participation is well represented in the literature as closely connected to interaction and sense of community. Indeed identity construction through interactions in an ongoing process of negotiation between self and others, and the impact this may have on the online learning experience, are not yet extensively researched phenomena 
(Perrotta, 2006; Hughes, 2007). On the other hand, identity formation in 'real' contexts has been widely discussed (see for example Gee, 2000; Norton, 2000; Bucholtz \& Hall, 2005; Richards, 2006; Norton, 2010), establishing that whenever people socialise, so too exist their identities - that is, a sense of who they are, and are becoming, in a process of dynamic formation and redefinition of self in response to the social context. When a student contributes to the online class in some way they engage in a process of portraying something of themselves to the group, with unfolding clues about who they are, what they know, what they value and how they think. Online learning communities, just like any other community, would not exist without the participation of these individuals, through which identity also emerges (Cunliffe, 2003; Hill, Watson, Rivers \& Joyce, 2007). For this reason this review couples identity formation with interaction leading to community building as unequivocally important in understanding what contributes to appropriate online pedagogies.

The purpose of this review therefore is to explore the literature in terms of how interaction contributes to building an online community in the context of higher education including the co-construction of knowledge, together with the impact that interaction affords for identity formation. This brings psychological and socioemotional dimensions to the fore, with online environments being more affected by social and cultural factors (Mercer, 2000). From this it may then be deduced that socioemotional considerations are important for any pedagogic endeavour that takes place in the online environment.

\section{Search strategy}

To ensure a focused review of the literature the following questions were proposed:

(1) What is the role of interaction in online learning?

(2) What fosters or inhibits community building in online learning?

(3) What affordances do interaction and sense of community give to identity formation and how might this explain sense of belonging/isolation in online higher education learning contexts?

Preliminary literature searches established that community, or 'sense of community' is closely connected to interaction and participation. Based on this, the first strategy was to set up a basic search model to be used across multiple databases such as Scopus, ERIC, Education+, ProQuest, ScienceDirect, Informaworld and Wiley Interscience, and was performed as a two-step process (see Appendix, Table 1). The first involved a combination of 'online learning', 'community' and 'interaction', searching for these terms in the abstract and/or titles of peer-reviewed articles. Synonyms were included for 'online learning' (such as distance learning, e-learning, online education, distance education, web-based learning) and for 'interaction' (such as discussion), as well as spelling variations of online (on-line). If there were an excessive number of results, these were managed through filtering (for example excluding some subject areas, or pre-1990s publication dates). Of the articles retrieved, the abstracts were read, discarding those deemed irrelevant to answering the questions. After synthesis of these results contributed to an understanding of questions 1 and 2, 'identity' was added to the search strand to explore the third question. This step had the effect of 
highlighting the small proportion of identity-specific articles that exist in the current literature. As an exercise to substantiate this a separate search of article titles containing 'identity' or 'identity + online' was performed across ERIC and Scopus. This exercise demonstrated clearly the disproportion of 'identity + online' articles to 'identity' only articles, with the results provided in Appendix, Table 2.

The next stage in the search strategy involved locating relevant literature from the reference lists of the retrieved articles. This provided useful leads to a range of literature such as other articles, journals and books. As a result the material gathered for this review represents a broad range of literature from across the globe.

The discussion section of this paper follows the sequence of the questions, firstly dealing with some of the issues around online interaction, which tend logically to lead to its impact on forming and sustaining online learning communities. Finally these two well-represented themes will be drawn together by considering the impact that identity construction has on interaction and community building, concluding with a short discussion on pedagogic implications.

\section{Interaction in online learning}

It is widely accepted that interaction is important for building interpersonal connections and conceptual understandings, and that it occurs differently in online contexts than in face-to-face situations. Online interactions are often via the keyboard such as synchronous chatrooms (i.e. in real time), or asynchronous discussion boards, emails, and blogs (i.e. unconstrained by time). Because flexibility around other work/life commitments is one of the main reasons for choosing distance study (Priest, 2007; Muller, 2008) this review will be largely focused on asynchronous communications, as these best support the demand for flexibility. In addition these are often the preferred method of interaction for educators, as the time delay allows students time to refine their responses before sending or posting, often resulting in a deeper level of thinking (Liu et al., 2007; Arend, 2009; Hull \& Saxon, 2009). Even so, Hughes (2007) points out that "flexibility provides learners with more opportunities to disengage as well [as to] engage" (p. 709), signalling some of the wider concerns around participation in online environments.

Asynchronous communication raises the issues of separation, different time zones, lack of opportunity to meet or interact in 'real' time as well as commitments aside from study, which immediately alert to the need for a different pedagogical approach. In traditional pedagogy, the practices of thinking together to build knowledge, community and connectedness (Vygotsky, 1978; Mercer, 2000; Alexander, 2008) are widely accepted. However, due to the way dialogue happens online, particularly asynchronously, these practices may not be directly transferrable from the face-to-face classroom. In online learning, the success of interaction may depend more so on a high level of rapport and cooperation built up between learners and their instructors (Goertzen \& Kristjánsson, 2007), often without the benefit of ever seeing or hearing each other (Rovai, 2002a). One obvious difference is the absence of usual meaning-making cues such as gesture, voice tone and interactive immediacy supporting negotiation of meaning and clarification. As such a more deliberate construction of the social setting may be necessary to ensure students feel included and self-assured, thus adding value to the group and to learning through active participation (Hughes, 2007). 
This is especially so for the fully delivered online course across different time zones where opportunities for real-time meetings are not an option. The necessity of interaction is not in question here, but an awareness of how to harness its benefits is, to boost intellectual and socio-emotional investment in the learning. The fact that isolation and lack of connectedness continue to be felt by students across culturally and linguistically diverse online environments (Birch \& Volkov, 2007; Bartlett, 2008; Uzuner, 2009) strongly suggests the presence of socio-emotional factors when interacting with others, of which online pedagogy needs to take account.

The major issues from the literature revolve around, not whether interaction is important, but how to encourage and sustain it. To this end the debate vacillates between whether participation should be compulsory or voluntary, and whether encouraging social interaction or task-driven interaction will better contribute to educational objectives.

\section{Compulsory participation or voluntary?}

Advocates of compulsory participation maintain that high levels of interaction can be encouraged if made an assessable component. Pelz (2010) argues that prolonged engagement with the content is directly connected to greater levels of learning for students. This, together with high visibility and involvement of the course instructor, will 'compel' learners to participate (Lapadat, 2007). In Lapadat's study, tutormodelling of appropriate interaction, negotiation strategies and critical thinking approaches, demonstrated that a good level of sustained interaction could be achieved, and provides some evidence for mandatory participation. Although Lapadat acknowledges this study was too small to generalise, and her involvement as the course instructor and co-designer makes it atypical, it does provide valuable insight into the potential for maximising participation, for catering for a diversity of online learners, and for creating an equitable learning experience.

While compulsory participation encourages regular contributions to discussion, it may also develop satisfaction in the learning experience. Interaction fosters interpersonal connections between group members and at the same time can help learners "feel their educational needs are being met" (Rovai, 2002a, p. 6). It can also be useful for encouraging students who may not feel comfortable in this relatively new semiotic domain (Gee, 2003) or who need extra 'incentive' to participate. Compelling students to interact may be a valuable strategy for shy students (Garrison, 2011), or second language learners who may be reluctant to contribute due to perceived language limitations, although this reluctance can be felt by many students regardless of language background (Brick, 2006).

Students though, often have mixed feelings about compulsory participation. There may be some students who are keen participants, and others who, for many reasons are not interested, impacting the whole group dynamics if participation is mandatory (Exter et al., 2009). Perceptions of compulsory participation were investigated by Birch and Volkov (2007), whose participants were a group of ESL/EFL (English as a second language / foreign language) students. These students were informed of the social and cognitive benefits of participation, which aimed to replicate their experience of on-campus tutorials. While the paper reported positive results overall, closer reading indicated small but perceptible differences in how students viewed compulsory participation. Peer interaction for the purpose of encouraging a 
sense of belonging, reducing isolation and developing friendships, was not rated as highly ('beneficial - quite beneficial') as instructor interaction through feedback or the development of effective electronic communications skills ('quite beneficial - very beneficial'). That participation connected to learning goals was regarded more highly than the maintenance of inter-group dynamics is perhaps unsurprising. However a different conclusion was reached by Skulstad (2005), in a study of trainee teachers of EFL who were required to participate in online discussion during their practicum. The tasks of critiquing each others' analyses of learner texts taken from the practicum, as well as responding to these comments, were intended to provide purposeful and authentic reasons to engage in 'EFL teacher discourse' and develop critical thinking skills. However the findings revealed that students were more concerned with 'saving face' socially, using strategies to downplay their growing expertise, rather than in demonstrating their knowledge. This suggests that although the production of interaction can be pre-determined by the task to a certain extent, the impact of some other factors, in this case cultural factors, such as face-saving, hedging and politeness strategies, may skew learning aims, and highlights the need for ongoing evaluation and facilitation, as well as close moderation to achieve desired outcomes (see also Coffin et al., 2005).

Proponents of voluntary interaction, on the other hand, believe exchanges between participants can be encouraged and sustained if provided in a "sound social space" (Kreijns, Kirschner, Jochems \& van Buuren, 2004), which is embedded into course design (Kirschner, Strijbos, Kreijns \& Beers, 2004). Kreijns and colleagues (2004) describe social space as:

"... the network of social relationships amongst the group members embedded in group structures of norms and values, rules and roles, beliefs and ideals ... a social space [is] 'sound' if it is characterized by affective work relationships, strong group cohesiveness, trust, respect and belonging, satisfaction, and a strong sense of community" (p. 608)

Creating a 'sound social space' which perpetuates the interaction necessary to sustain it, is possible through collaborative group work. This lends itself well to enhancing work and social relationships leading to an affinity together as a community of learners (Kirschner et al., 2004; Hull \& Saxon, 2009). If authentic problem solving tasks are used, the need to interact contributes to a sense of achieving shared goals, which can contribute to group relationships and cohesiveness as learners involve themselves in the co-construction process. Indeed the functional role of collaborative talk can stimulate extended interaction creating a more cohesive group who have shared responsibility for the outcomes (Kirschner et al., 2004; Yeh, 2010) and does not require grading to sustain it. Voluntary participation in online group work was investigated by Brindley, Walti and Blaschke (2009) in a longitudinal three year study. Online discussion postings were collected from over 15 cohorts during this time, with two of these being ungraded. Due to the collaborative nature of group work, the authors found that students were just as active in the tasks even when ungraded. It seems that voluntary participation 'works' with clear collaborative strategies that encourage purposeful student interactions as well as for building up a social space where students can develop relationally.

Regardless of whether participation is assessed or not, the studies discussed above affirm that interaction is pedagogically desirable for online learners. The issue 
under contention is how best to achieve sustained levels of interaction in practice. This leads to another aspect in the debate which focuses on the type of interaction students engage in. Some educators advocate for 'quality' in interaction that is connected to learning objectives, while others value more socially oriented interaction. While this divide is apparent in much of the literature, another consideration must be the interactive purpose, which is often the determiner of what is produced in discussions.

\section{Task-oriented or relationship-oriented interaction?}

When meeting together occurs through asynchronous and text-based communications, the ensuing participation raises the issue of what type of interaction and how much interaction might be appropriate for the purposes of the online class. One argument is that interaction which fosters deep learning best suits the purposes of higher education. Garrison and Cleveland-Innes (2005) make a distinction between the voluminous 'quantity' of interaction often seen in social discourse and the more critical discourse they regard as 'quality', proposing that while there is some value in social interaction for building community, a 'higher level of discourse' is more important. They state that,

\footnotetext{
"high levels of interaction may be reflective of group cohesion but it does not directly create cognitive development or facilitate meaningful learning and understanding" (Garrison \& Cleveland-Innes, 2005, p. 135)
}

This is echoed by Hill, Song and West (2009), who noted an increase in meaningful interaction over the course duration, revealed in "indepth online messages" (p. 91). However critical discourse can sometimes be hindered by concerns for nurturing a positive interpersonal environment, reducing the depth of engagement and development of these important skills (Coffin, Hewings \& North, 2012). Levels of engagement in interaction can be influenced by many variables including cultural factors, involvement of the tutor, tutor moderating skills, access to materials, levels of support, feedback, access to others' ideas, as well as "insecurities about learning" (Owens et al., 2009, p. 56), especially for students returning to study after a break or if attitudes or values are culturally diverse (Cleveland-Innes \& Sangrà, 2010). In regard to accessing others' ideas, this requires that 'others' are willing to disclose, which will not occur unless there is some level of trust. This can only be built over time through connecting interpersonally (Rovai, 2002a; Gulati, 2008; Yeh, 2010). While the emphasis on the nature and quality of interaction may be the "overarching issue" (Owens et al., 2009, p. $69)$, consideration needs to be given to insistence solely on producing indepth responses. This may have ramifications for 'lurking' or insecure students (Gulati, 2008) who may need to develop confidence through building supportive social connections first, before becoming willing to self-disclose.

The debate around quality in interaction or quantity of messages, continuing the terms used by Garrison and Cleveland-Innes (2005), signals that interaction serves different purposes. Asynchronous interaction is more often associated with depth of learning while chatrooms are not, with the tendency for instructors to view chatrooms as having more social value than as a potential learning tool. This notion is challenged in Tudini's study (2003) in which some students expressed the learning value of being able to engage in real-time talk with each other. To this end, Rovai (2002a) makes a distinction based on dialogic purpose, by identifying two types of interaction - one for task-oriented learning and the other for meeting socio-emotional needs which are relationship-focused. Rovai (2002a) argues that both are necessary but that "socio- 
emotional-driven interaction is largely self-generated" (p. 5), while the instructor has more control over task-oriented interaction. Social interaction helps build trust and familiarity with others, potentially affecting students' feelings towards the learning experience with some impact on motivations. This must influence the extent of participation in the learning activities, which do not exist in isolation from the "broader systems of relations in which they have meaning" (Lave \& Wenger, 1991, p. 53). Rovai (2002a) found that students made more meaningful connections when they were engaged in different types of interaction, which he identified as playing diverse, but important roles. Moving from the getting-to-know-you stage towards contributing interpersonally and intellectually to the group often occurs in incremental stages, with the early stages of building friendships through frequent interaction being essential.

Arguably, an abundance of social interaction can be likened to 'thinking out loud' and from the contributions of others also thinking out loud, there emerges some depth in the process of co-construction of knowledge (Vygotsky, 1978; Mercer, 2000). This perspective can be understood as the learning value of interaction being realised in its dialogic development, thus rendering the product as secondary to the process. If only indepth interaction is demanded, the discussion may miss important increments in the learning process that are born from shared cumulative thinking.

\section{The 'elephant in the room'}

Regardless of the debate around interaction, mature-age, part-time students who are often the learners enrolled in distance courses (Rovai, Wighting \& Liu, 2005), are more than likely juggling responsibilities and commitments in addition to the demands of study. It needs to be acknowledged that the reality for them may be that even if a desire exists to interact, developing interpersonal relationships may not be a high priority. In Owens and others' study (2009) it was found that these types of students are likely to be "goal oriented and [assessment] focused" (p. 62) with little interest in social interaction. This concurs with a response from one of Exter and colleagues' (2009) participants who felt satisfied with the challenge of the course content but "... the other parts, community, and all that ... I'm an old fart, that's just not what I need in my life" (p. 189). This could also be explained as some not strongly identifying themselves as a member of that particular community (Hughes, 2007). Others may simply dislike having to comply to 'forced' participation (Arend, 2009).

Despite Birch and Volkov's (2007) positive findings overall, almost a third of the ESL/EFL students said they would choose not to participate if discussion was voluntary. Yet while some students feel little need to interact, others feel that only their classmates can understand their issues (Liu et al., 2007) and the collegial support and networking becomes a very important priority (Exter et al., 2009). Interestingly Liu and colleagues (2007) reported that some students were resigned that online could not mimic face-to-face and that a lack of connectedness was the 'trade-off' for the convenience of flexibility.

It also needs to be acknowledged that some faculty staff may not actively encourage the use of discussion in their online classes (Mitchell \& Geva-May, 2009). This could be due to a lack of awareness (or even perhaps acute awareness) of the different pedagogical requirements for online learning, or of the benefits of building community. There could also be uncertainties about what to do with tutorial-like 
discussion which, unlike verbal discussion - 'disappearing' once uttered - is given permanence on the discussion space, and may seem to be inviting some form of assessment, with the resultant flow-on to workload (Pelz, 2010). In fact findings from Mitchell and Geva-May's study (2009) of faculty attitudes towards online learning, show a level of resistance from faculty staff, particularly in relation to the change of practice required to meet the different needs of online learners (see also Exter et al., 2009). This could be related to workload as online instructors often are managing multiple roles (White, 2003) as well as the time it takes to provide the individual and timely feedback expected by the students (Bailey \& Card, 2009; Koh \& Hill, 2009). In addition, adapting to a different pedagogic approach requires "flexibility and a shift in mindset" (White, 2003, p. 69; see also Salmon, 2005), placing challenges on mental energies as well as on time (Kelly \& Stevens, 2009).

\section{The online learning community}

As social beings the socio-emotional desire to belong is a fundamental human need (Maslow, 1968) and has been seen historically through geographically defined communities. In recent years however, the boundaries defining 'community' have shifted dramatically, with ease of travel and communications technology making it possible for communities to develop beyond time, space or the physical proximity of its members (Rovai, Wighting \& Lucking, 2004). By no longer needing a physical locality to exist, the emergence of online contexts have redefined traditional notions of community by making it accessible to a diverse and widely distributed membership, in which it becomes the shared interests that denote the community (Mercer, 2000; also see for example Perrotta, 2006). Without the restrictions of physical or geographical location, community becomes "what people do together" rather than "where or through what means" (Rovai, 2002a, p. 4). An understanding of what may constitute an online community can be found in the Communities of Practice framework. This framework operates a structure of community comprised of diverse members involved in multiple levels of participation and communal negotiation, from which the shared pursuit creates meaning making resources in the process of becoming part of the 'in-group' (Wenger, 1998). The community is defined by the practice its members are mutually engaged in, which necessarily involves interaction, and is described by Lave and Wenger (1991) as "a set of relations among persons, activity, and world, over time and in relation with other tangential and overlapping communities of practice" (p. 98). The communities of practice framework emphasises engagement in some kind of practice as essential for developing community, rather than on the physical or geographical proximity of its members. This portability of community has great potential for virtual classrooms.

In the context of education, a community is built through cooperative and reciprocal exchanges in supporting each others' learning and is crucial for building knowledge (Alexander, 2008). Community 'happens' through dialogic exchanges where pooling of individual mental resources along with appropriate support results in cognitive development beyond individual mental capacity (Vygotsky, 1978; Brown \& Cole, 2000; Mercer, 2000; Bower \& Richards, 2006). In this regard the literature is clear about the fundamental role of interaction in bringing an online learning community into existence, and for building and maintaining interpersonal relationships. In a learning environment where a community may be short-lived or seem contrived, how much socio-emotional investment is channelled into study-related relationships is an individual choice which can impact the development of community. Rovai (2002b) 
argues that community involves a deeper emotional response that is more than just sharing ideas and resources, but where membership is signified by "strong feelings of community" (Rovai, 2002a, p. 199). This suggests that socio-emotional investment is needed before feelings of community can emerge, and expressed as a sense of belonging, trust between members, shared expectations and learning goals, and a level of concern for each other (Rovai, 2002a). This is not to claim that community is homogenous, but rather that communal negotiation allows for diversities in the pursuit of joint endeavours (Wenger, 1998). The result is a shared commitment and faith that individual needs will be met within the community (Dawson, 2006).

In line with Rovai's (2002a) distinctions of task-oriented and relationshiporiented interaction, Rovai and colleagues (2005) highlight the operation of two different online communities - 'social' community, where interaction fulfils a need for friendship; and 'learning' community where learning goals drive the interaction. While the distinction is being made, in practice this may not always be clear-cut, as learners are quite adept at using 'talk' to achieve different purposes, often concurrently. For example using hedging devices to tone down a critique of another's work can safeguard relationships at the same time as fulfilling institutional requirements, as shown in Skulstad's study (2005). This distinction is not to say that one is more important than the other, as it is often the social which precedes learning-oriented interaction. What this does allude to however is that students take on a number of roles when engaged in learning. These can at times be competing roles (Skulstad, 2005), such as the role of a friend or student, novice or expert and requires a level of skill and awareness when balancing learning goals with social harmony of their community.

\section{Enacting a sense of community in online learning}

While 'community' can be defined as being developed around shared goals, interests and experiences through what group members do collectively and cumulatively, 'sense of community' is the individual perceptions of community. It is an emotional response to relationships between group members, and where one perceives themselves positioned socially can determine their interpersonal investment in the community, resulting in a connecting or isolating effect.

Lack of sense of community or feeling disconnected from the learning community are key issues for online learners (Rovai, 2002a; White, 2003; Hughes, 2007; Gallagher-Lepak, Reilly \& Killion, 2009). Insight from the learner perspective into factors contributing to building community has been the driving force behind many studies (such as Rovai, 2002b; Ouzts, 2006; Bartlett, 2008; Exter et al., 2009) with a strong connection between sense of community and student satisfaction (Rovai, 2002c; Dawson, 2006; Liu et al., 2007; Koh \& Hill, 2009). Liu and others (2007) propose links between sense of community to perceived learning, as well as perceived learning outcomes to student satisfaction. In addition, they found that feeling a sense of community lowered feelings of isolation as well as the risk of attrition, substantiating similar findings such as Owens and colleagues (2009). In response to lingering concerns of distance education being inferior to on-campus classes, the connection between feeling isolated and attrition rates prompted the study by Owens and colleagues (2009). These authors found that there were multiple 'outside' factors which impact on sense of community including course content, teaching staff, the technology and course delivery support, the type of communication engaged in or expected, as well as the 'inside' 
influences or "psychosocial factors" (p. 56) which can be a significant determiner in student perceptions, success and experience.

Sense of community is directly impacted by the extent of interaction between group members. A comparative study conducted by Exter and others (2009) found that only a quarter of online students regularly interacted while almost all the on-campus students in the study engaged in multiple weekly interactions. In light of this, the authors discuss the responsibility that some online students felt was theirs for actively creating a sense of community, while also being aware that others in their group did not share this same level of enthusiasm (see also Hughes, 2007). This indicates the potential for disappointment resulting from a mismatch in expectations, even if students do understand the competing obligations and demands on time that their classmates experience. Notwithstanding, of significance for these off-campus students was to be recognised and remembered by peers and staff with sense of community being impacted negatively if students felt unknown or anonymous (Exter et al., 2009). The need for recognition is intrinsically linked with being able to portray who we are. Identity construction has potential ramifications on motivation to participate, the extent of selfdisclosure, as well as on self-confidence and self-assurance. This may be viewed as an ongoing process in which aspects of identity emerge and are responded to, which then feed back into the community (Penuel \& Wertsch, 1995; Gee 1999, 2000).

Consequently the focus now turns to the impact that identity formation has on interaction and community building in online learning environments.

\section{Identity}

From the previous discussion it is clear that the literature makes consistent connections between interaction and sense of community. Yet identity, which plausibly and naturally emerges from any social interaction, is much less (explicitly) explored in online education research (Hughes, 2007). Database searches conducted according to the steps outlined in the 'Search Strategy' section (and detailed in the Appendix), revealed a disparity in the current literature that explores online identity formation, although the relatively new phenomenon of online learning and the challenge that virtual identity conjures could in part account for this. Because of the novelty of online identity research, this section will firstly discuss a conceptual framework, from which online identity formation may then be understood within the larger context of research.

\section{Conceptualising identity: a social construct}

Exploring the notion of identity formation is first necessary in order to frame identity in the context of online learning. Most significantly identity is socially constructed, being forged through human involvement in social activity. During the process of making it clear to others (and to oneself) about who you are and what you do (Gee, 1999; Henderson \& Bradey, 2008), identity constructs, and is constructed by, language (Penuel \& Wertsch, 1995). This occurs within a group of people who, through social interactions, share some kind of "distinctive practices" (Gee, 2000, p.105).

From a sociocultural perspective, human activity is mediated by language in interacting moments, which is intrinsically linked to consciousness and higher mental functioning (Vygotsky, 1978). Although Vygotsky did not talk about identity as such, a sociocultural approach to forming identity can be considered when individual functioning is viewed as inseparable from sociocultural processes. The centrality of 
dialogue in community and co-construction of knowledge is coupled with its centrality in the construction of identity in continual negotiations between self and others. Identity formation therefore is as much about the sociocultural processes as the individual.

When applied to the context of the online classroom, in particular asynchronous communications, interacting moments are evidenced in what is written and placed in the 'public' group space. These texts represent thoughts, responses, re-casting of knowledge, values and attitudes, which are manipulated for an intended audience in a particular social context. Underlying these is the accumulation of life experience continually being augmented in a dynamic and influential process, along with changing perceptions of self and others (Perrotta, 2006). In the language we choose to use, something of 'who we are' will emerge (Ivanič, 1998).

\section{Identity and the 'discoursal' self}

To date much of the research on identity has been conducted in physical locations with participants who can be observed in 'real' contexts. Physical and verbal clues to identity formation are readily observable as well as non-verbal semiotics occurring during the interplay between participants, their contexts and their (unfolding) perceptions of self and others (Norton, 1997; Norton, 2000; Beijaard, Meijer \& Verloop, 2004; Varghese, Morgan, Johnston \& Johnson, 2005; Kanno \& Stuart, 2011). In online environments, when the social meeting space is entirely a construct of written language, lacking any of these contextual factors, the evidence of identity construction must be found in the disembodied text of discussion boards or chatrooms. Despite this, Burgess and Ivanič (2010) argue that identity will emerge in all social practices, a stance also taken by Richards (2006). This has been described as 'discoursal identity' as the written text will contain something of the writer's identity, which in turn will be interpreted by the reader (Olinger, 2011). Even in the context of academic writing, often regarded as void of the subjective self, Ivanič (1998) found that authors bring their "discoursal repertoires" (p. 181) to the writing, influenced by cumulative life experience, as do their readers to the interpretation. Ivanič states that "who we are affects how we write, whatever we are writing" (1998, p. 181) (emphasis added), indicating the often unconscious interplay of the sociocultural and socio-emotional with subjectivity in what is written.

Identity as emerging from written text, such as asynchronous interactions, can be viewed therefore as a product of interpersonal relations and sociocultural processes. It can be understood as emergent and socially-dependent, being "shaped moment by moment" (Bucholtz \& Hall, 2005, p. 591) by the social context, perceptions of values, power-play and the social positionings brought to the online context by contributors (Perrotta, 2006). In fact, these perceptions of identity are formed, often unconsciously, when readers draw clues about others from the information presented, but also from what is left 'unspoken' (Hughes, 2007).

\section{Identity research in online contexts}

To date research into identity formation in online learning contexts is limited. However from the literature reviewed, interaction is fundamentally involved in the process of constructing identities. Therefore this discussion will focus on issues raised in the literature most pertinent to belonging/isolation, such as the challenge of managing the incongruent identities of dissimilar members (Hughes, 2007), and the impact of this on 
learning. The position taken is that identity and learning are intrinsically linked (Wenger, 1998).

Diversity is a 'fact of life' but not often overtly mentioned when discussing online community building. However the identity trajectory may provide an explanation for why certain students engage with or invest in the learning community, and why others exclude themselves, or are excluded. An individual's perception of how they are perceived by others and their positioning in the learning group can impact the extent of interpersonal and intellectual engagement, and consequently their experience of distance learning. Differences in identities that result in exclusionary behaviour towards others, have been described by Hughes (2007) as 'incongruence' in identities. The effect of incongruent identities in online classrooms is perhaps one of the most 'lived', but least identified phenomena contributing to participation levels and retention concerns (Hughes, 2007). Hughes cites a typical example of the student who may not conform to class expectations, such as coming late into forum conversations, or seeming not to pull their weight in group collaborations, causing anxiety for other group members. Indeed Yeh (2010) describes such behaviour as 'trouble-maker', which was viewed as a hindrance to the development and functioning of the online community. But rather than sidelining the issue of incongruent identities by assigning 'trouble-maker' to these students or accepting this as an inevitability in online learning, Hughes (2007) extends a challenge to the community, which she claims has some responsibility for finding ways to embrace the diversity displayed by others. This must also be a tutor priority (Irwin \& Hramiak, 2010). Hughes (2007) makes the suggestion that rather than expect the habitual latecomer to conform to the status quo, that the community change their posting behaviours to accommodate their non-conforming peer. There are many valid reasons why reconfiguring behaviours for learning online can lead to incongruent identities, and not all learners will embrace the disembodiment factor. For some personalities and learner styles, this presents challenges particularly being physically non-existent and existing instead as "expressed identities in virtual space" (Ke, Chavez, Causarano \& Causarano, 2011, p. 350). These are very real socio-emotional issues at the core of the learner, for if an individual perceives they are not recognised or valued by the community, particularly given the challenges presented by learning online, then the flow-on effects of incongruent identities to interaction, community, learning, and motivation could well be at stake. Conversely, congruence in identities, or inclusion despite diversities, is more likely to have positive socio-emotional effect, encouraging motivation to participate, and hence increase the potential for a more emotionally and intellectually stimulating learning experience.

Power in relationships and culture also impact on identity (in)congruence. An investigation by Perrotta (2006) explored online forums which were established to cater for more or less experienced psychologists in Italy. Operating as open-ended forums, unlike the 'usual' semester-bounded discussion forums in educational contexts, these discussions continued over many years, allowing an extended view of the unfolding issues. Using Bourdieu's approach to explain the cultural capital held by an academic psychology degree, Perrotta found participants with these credentials saw a responsibility to protect what they perceived to be the common identity of 'psychologist', using the power of their cultural capital to diminish the authority of those without the same credentials. Similarly Irwin and Hramiak (2010) found evidence of 'them and us' identities in the online contributions of trainee teachers during their practicum. Discourse analysis of personal pronoun use indicated the vacillations 
between novice and professional identities, between feeling like an outsider or an insider in the teaching community. These highlight one of three paradoxes suggested by Hughes (2007), that the inclusion of one identity can render the exclusion of another. Perrotta (2006) noted that the construction of a common professional identity "will always involve a commitment, often unconscious, to a systematic bid to gain more power" (p. 462). This was also captured to a degree by Ke and others (2011) in their examination of discursive practices in the online interactions suggesting that "power, inequality and relations between social groups" (p. 356) at the macro level of meaning will frame how the text is interpreted, while the text itself is framed by the presence of the students' identity at the micro-level of meaning. From the abovementioned it is evident that identity construction will almost always involve an element of power-play, overt or not, impacting on the self-assurance of those lacking the valued cultural capital of a particular community.

Learning and identity are intrinsically linked, a connection highlighted by Wenger (1998) as "all learning eventually gain[ing] its significance in the kind of person we become" (p. 226). In the space of the discussion forums students communicate what they know of the content, but also (even if unconsciously) present their identities "by communicating who they are and how they perceive others" (Ke et al., 2011, p. 350). The interconnectedness of interaction in the processes of identity expression, knowledge building as well as maintenance of trust and rapport is strongly argued by Ke and colleagues (2011) as only achievable through participation in online discussions. This is supported by Yeh (2010), who measured the success of online communities through the roles taken on by students indicated by collaborative and meaningful participation behaviours. Yeh's interpretations are drawn from the community of practice and community of learners models in which interdependence between students is necessary for cognitive learning to occur (see also Hull \& Saxon, 2009). As identity is negotiated socially, and as the learning community is comprised of a diversity of learner identities, this inevitably presents tensions in the levels of collaboration and participation, hence extending to the potential for learning (Skulstad, 2005). On the other hand, identities which are "well-articulated" (Ke et al., 2011, p. 351 ) and favourably recognised and reciprocated by the community, are conducive to academic and interpersonal success.

\section{Online pedagogy and task design}

While investment in interaction increases the potential for knowledge-building, it is also clear that this will be enhanced by encouraging students' emerging identities, which unfold and evolve dynamically over time. According to Alexander (2008) what we believe about pedagogy is played out practically in the act of teaching, therefore task design is crucial for creating opportunities for identity to develop. This is a paper in itself, but because pedagogical principles and issues were invariably raised in the literature reviewed, some require mentioning.

As interaction has been clearly established as a key component in creating an online learning community, the challenge is how to inspire interaction that also allows the interactants opportunities to construct and negotiate their various identities. Carefully managed and monitored interaction that elicits most from the students (Hill et al., 2009) must be balanced with the typically short time duration of an online subject. Hill, Song and West (2009) argue that simply providing a resource for interaction does 
not mean it will be utilised, also echoed by Garrison and Cleveland-Innes (2005). This is reflected in the following which represent a selection of the pedagogy-related themes.

Task type

Identity presence will be greatly influenced by the task type, such as open ended and sociocultural related discussions (Ke et al., 2011); collaborative, purposeful, relevant, task-driven discussion tasks (Warschauer, 1997; Kirschner et al., 2004; Goertzen \& Kristjansson, 2007; Arend, 2009; Brindley et al., 2009); and introductions and 'icebreakers' (Pelz, 2010; Xie \& Ke, 2011). However, Hughes (2007) highlights the tension between students knowing too much or too little about others, which raises the challenge for educators to balance how much students really need to know about each other in order to encourage identity formation in a way that contributes favourably to the learning environment.

\section{Explicitness}

The absence of many of the meaning making cues usually relied on necessitates clear and unambiguous guidelines in online learning, such as explicit protocols for performing online discussions; providing understanding about the social purpose and audience of the discussions; explicitness of roles and responsibilities to encourage higher levels of thinking (Arend, 2009; Hull \& Saxon, 2009; Ke et al., 2011); upfront awareness about the purposes of tasks and discussions (Kelly \& Stevens, 2009); as well as foreseeing potential misunderstanding and specifically addressing it before it leads to misinterpretation (Pelz, 2010). Finely balanced with this is the caution that such explicitness does not create incongruence of identities so that one person cannot be interpreted as privileged or preferred over another (Hughes, 2007).

\section{Instructor role}

Throughout this paper the implicit assumption is that the instructor plays a crucial role in online classroom interactions. Instructor decisions will impact what can happen between class members as opportunities for engagement and learning are largely orchestrated and steered by the instructor through facilitation, structure, leadership, modelling and explicit guidelines (Garrison \& Cleveland-Innes, 2005; Hull \& Saxon, 2009; Garrison, 2011). In this role, setting expectations around student participation, creating a safe social environment in which this can occur, as well as providing an appropriate level of moderation/intervention, are decisions which have strong potential ramifications on students' engagement and identity expression. Therefore careful consideration needs to be made around designing in the desired or most suitable interaction - i.e. more 'natural' or more structured?, voluntary or mandatory? (Rovai, 2002a; Kreijns et al., 2004); deciding appropriate instructor intervention and guidance in argumentation skills development (Coffin \& Hewings, 2005); structuring the social space to encourage learning as well as building up trust and rapport (Kirschner et al., 2004; Kreijns et al., 2004; Gulati, 2008); providing timely and appropriate feedback (Bailey \& Card, 2009; Koh \& Hill, 2009); and very importantly, having an adequate knowledge of one's students so they feel known and recognised (Exter et al., 2009), thus helping to validate their identity and thwart feelings of isolation. 


\section{Instructor reactions and involvement}

How an online instructor reacts is possibly more crucial than their level of involvement in the discussions (Ke et al., 2011), impacting on socio-emotional well-being perhaps more so than in face-to-face situations. Expression of identity from students is more likely when instructors value contributions drawn from personal experience by rewarding or highlighting meaningful posts; when the tutor probes for elaboration that allows students to incorporate their identities into the learning; and where instructors share from their own personal perspective rather than always displaying their academic identity (Irwin \& Hramiak, 2010; Ke et al., 2011). This not only brings a sense of reality to the virtual tutor, but also models appropriate identity discourse in learning, which Richards (2006) sums up nicely in the following:

"... if there is indeed a compelling case to be made for conceptualizing our interactional work as teachers in ways that engage both the discoursal and the personal, we must also recognize that any actions arising from this will involve an investment of self, with all the emotional, relational, and moral considerations that this invokes" (p. 72)

\section{Conclusion}

From the literature reviewed it would appear that the identity trajectory needs careful consideration in online learning, if the goal of education is for the learner to really engage in the learning. Over the duration of the subject being undertaken 'identity trajectory' may be a way of understanding the opportunities for engagement that are taken up or constrained by perceptions of one's identity, as impacted by socially negotiated relationships and positionings. The socio-emotional challenges associated with developing one's disembodied identities can be a significant determiner of participation levels, sense of community (or isolation), as well as of motivation and satisfaction, with potential ramifications on learning. Without doubt the role of interaction is fundamental to identity construction, community building and learning. When there is an imbalance or breakdown in interaction this results in other issues such as feeling isolated, reduced confidence, non-participation, reluctance to contribute, 'trouble-making' and so on. These may well be symptomatic of incongruent identities, while on the flip-side congruence of identities is more likely to foster engagement in the learning community with increased likelihood of sustained investment in academic and interpersonal pursuits. Indeed the challenge for the instructor, who plays a crucial role in the learning process, is for identity to be managed in way so that one identity is not seen to be privileged over another, and hence one person over another (Hughes, 2007; Irwin \& Hramiak, 2010). Socio-emotional factors are necessarily involved as individuals construct their identities, respond and are responded to during interactions in the learning community, and from which a sense of belonging (or not) can result, leaving little doubt of some kind of impact on learning, and the online learning experience.

As a result it is hoped that some of the issues raised from this review stimulate further exploration of what is at the core of learners and learning, particularly the impact on learning that identity has in online environments. The influence of cultural factors is one area that would greatly contribute to our understandings of identity in online learning, and would merit a literature review in its own right, which cannot fit in the limited space of this paper. This becomes even more pertinent when considering the opportunities that internet technologies provide for cultural diversity to exist as the 
'norm' rather than the exception. From the literature reviewed here it seems clear that online learners, perhaps more so than face-to-face learners, need deliberately orchestrated, multiple opportunities to engage with others so that expression, development, tolerance and recognition of their diverse identities may in part compensate for any lack felt by not having a physical presence.

\section{APPENDIX}

\section{Basic Search Model}

\begin{tabular}{l}
\hline Step 1: \\
[online learn* OR on-line learn* OR distance \\
learn* OR e-learn* OR web-based learn* OR \\
online education OR on-line education OR \\
distance education] \\
AND [communit*] \\
AND [interact*] OR [discussion] \\
in the abstract and/or title and/or keywords \\
$\checkmark$ peer-reviewed (if this option is available) \\
Step 2: \\
AND [identit*]
\end{tabular}

$\dagger$ as at 3 February 2012
Number of articles retrieved $\dagger$

$\Rightarrow$\begin{tabular}{lll|}
\hline ERIC & Scopus \\
& $\Rightarrow 7$ & 284 \\
12 (after filtering) & 156 (after filtering) \\
& \\
& \\
1 & \\
1 (after filtering) & 5 (after filtering) \\
\hline
\end{tabular}

Table 1: Basic search model and example of results across two databases

\section{Search Criteria}

\begin{tabular}{|c|c|c|}
\hline & ERIC & Scopus \\
\hline $\begin{array}{l}\text { 1. [identit*] in article title } \\
+ \text { peer reviewed } \\
+ \text { journal articles only } \\
+ \text { higher education only }\end{array}$ & 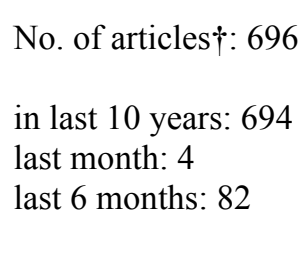 & $\begin{array}{l}\text { No. of articlest: } \\
29,686 \\
\text { in 2012: } 71 \\
\text { in 2011: } 2405 \\
\text { in 2010: } 2430\end{array}$ \\
\hline $\begin{array}{l}\text { 2. [identit*] AND [online] in article title } \\
(+ \text { criteria as above })\end{array}$ & $=0 / 696$ & $=85 / 29,686$ \\
\hline $\begin{array}{l}\text { Percentage of articles on 'identity' compared to those on } \\
\text { 'identity and online' }\end{array}$ & $0 \%$ & $0.29 \%$ \\
\hline
\end{tabular}

$\dagger$ as at 3 February 2012

Table 2: Comparative search for 'identity' and 'identity + online' in article titles 


\section{References}

Alexander, R. (2008). Essays on Pedagogy, Abingdon UK, Routledge.

Arend, B. (2009). Encouraging Critical Thinking in Online Threaded Discussions. Journal of Educators Online. 6(1). pp 1-23.

Bailey, C. J. and Card, K. A. (2009). "Effective pedagogical practices for online teaching: Perception of experienced instructors." Internet and Higher Education. 12. pp152-155. doi: 10.1016/j.iheduc2009.08.002

Bartlett, C. (June, 2008). Facilitating online interactions using community building strategies. University of Wollongong Faculty of Education Emerging Technologies Conference. University of Wollongong.

Beijaard, D., Meijer, P. C. and Verloop, N. (2004). Reconsidering research on teachers' professional identity. Teaching and Teacher Education. 20(2). pp 107-128. doi: 10.1016/j.tate.2003.07.001.

Birch, D. and Volkov, M. (2007). Assessment of online reflections: Engaging English second language (ESL) students. Australasian Journal of Educational Technology. 23(3). pp 293306.

Bower, M. and Richards, D. (2006). Collaborative learning: Some possibilities and limitations for students and teachers. 23rd Ascilite Conference: Who's learning? Whose technology? Macquarie University.

Brick, J. (2006). Academic culture: A student's guide to studying at university, Sydney, NCELTR Macquarie University.

Brindley, J. E., Walti, C. and Blaschke, L. M. (2009). Creating Effective Collaborative Learning Groups in an Online Environment. International Review of Research in Open and Distance Learning. 10(3). pp 1-17.

Brown, K. and Cole, M. (2000). Social Shared Cognition: System Design and the Organization of Collaborative Research. In Theoretical Foundations of Learning Environments. Jonassen, D. H. and Land, S. M. (Eds.). New Jersey USA, Lawrence Erlbaum Associates: pp197-214

Bucholtz, M. and Hall, K. (2005). Identity and interaction: a sociocultural linguistic approach. Discourse Studies. 7(4-5). pp 585-614. doi: 10.1177/1461445605054407.

Burgess, A. and Ivanič , R. (2010). Writing and Being Written: Issues of Identity Across Timescales. Written Communication. 27(2). pp 228-255. doi: 10.1177/0741088310363447.

Cleveland-Innes, M. and Sangrà, A. (2010). "Leadership in a New Era of Higher Distance Education". in An Introduction to Distance Education: Understanding Teaching and Learning in a New Era. Cleveland-Innes, M. and Garrison, D. R. (Eds) New York, Routledge: pp 227-247

Coffin, C. and Hewings, A. (2005). Engaging Electronically: Using CMC to Develop Students' Argumentation Skills in Higher Education. Language and Education. 19(1). pp 32-49. doi: 10.1080/09500780508668803.

Coffin, C., Hewings, A. and North, S. (2012). Arguing as an academic purpose: The role of asynchronous conferencing in supporting argumentative dialogue in school and university. Journal of English for Academic Purposes. 11(1). pp 38-51. doi: 10.1016/j.jeap.2011.11.005.

Coffin, C., Painter, C. and Hewings, A. (2005). Patterns of debate in tertiary level asynchronous text-based conferencing. International Journal of Educational Research. 43. pp 464-480.

Cunliffe, A. L. (2003). Intersubjective Voices: The Role of the 'Theorist'. Administrative Theory \& Praxis. 25(4). pp 481-498. 
Dawson, S. (2006). A study of the relationship between student communication interaction and sense of community. The Internet and Higher Education. 9(3). pp 153-162. doi: 10.1016/j.iheduc.2006.06.007.

Exter, M. E., Korkmaz, N., Harlin, N. M. and Bichelmeyer, B. A. (2009). Sense of Community within a Fully Online Program: Perspectives of Graduate Students. Quarterly Review of Distance Education. 10(2). pp 177-194.

Gallagher-Lepak, S., Reilly, J. and Killion, C. M. (2009). Nursing student perceptions of community in online learning. Contemporary Nurse. 32(1-2). pp 133-146.

Garrison, D. R. (2011). E-Learning in the 21st century: a framework for research and practice, $2^{\text {nd }}$ Edn. New York, Routledge.

Garrison, D. R. and Arbaugh, J. B. (2007). Researching the community of inquiry framework: Review, issues, and future directions. The Internet and Higher Education. 10(3). pp 157172. doi: 10.1016/j.iheduc.2007.04.001.

Garrison, D. R. and Cleveland-Innes, M. (2005). Facilitating Cognitive Presence in Online Learning: Interaction Is Not Enough. American Journal of Distance Education. 19(3). pp 133-148. doi: 10.1207/s15389286ajde1903_2.

Garrison, D. R. and Vaughan, N. D. (2008). Blended Learning in Higher Education, San Francisco CA, John Wiley \& Sons Inc.

Gee, J. P. (1999). An introducton to Discourse Analysis: Theory and Method, London, Routledge.

Gee, J. P. (2000). Identity as an Analytic Lens for Research in Education. Review of Research in Education. 25(1). pp 99-125. doi: 10.3102/0091732X025001099.

Gee, J. P. (2003). What Video Games Have to Teach us About Learning and Literacy. Gordonsville VA USA, Palgrave Macmillan.

Gilbert, J., Morton, S. and Rowley, J. (2007). e-Learning: The student experience. British Journal of Educational Technology. 38(4). pp 560-573. doi: 10.1111/j.14678535.2007.00723.x.

Goertzen, P. and Kristjánsson, C. (2007). Interpersonal dimensions of community in graduate online learning: Exploring social presence through the lens of Systemic Functional Linguistics. The Internet and Higher Education. 10(2007). pp 212-230. doi: 101016/j.iheduc.2007.06.005.

Gulati, S. (2008). Compulsory participation in online discussions: is this constructivism or normalisation of learning? Innovations in Education and Teaching International. 45(2). pp 183-192. doi: 10.1080/14703290801950427.

Gunawardena, C. N. and Zittle, F. J. (1997). Social presence as a predictor of satisfaction within a computer-mediated conferencing environment. American Journal of Distance Education. 11(3). pp 8-26. doi: 10.1080/08923649709526970.

Henderson, M. and Bradey, S. (2008). Shaping online teaching practices: The influence of professional and academic identities. Campus-Wide Information Systems. 25(2). pp 85-92. doi: $10.1108 / 10650740810866585$.

Hill, A., Watson, J., Rivers, D. and Joyce, M. (2007). Key Themes in Interpersonal Communication, New York, Open University Press.

Hill, J. R., Song, L. and West, R. E. (2009). Social Learning Theory and Web-Based Learning Environments: A Review of Research and Discussion of Implications. American Journal of Distance Education. 23(2). pp 88-103. doi: 10.1080/08923640902857713. 
Hughes, G. (2007). Diversity, identity and belonging in e-learning communities: Some theories and paradoxes. Teaching in Higher Education. 12(5-6). pp 709-720. doi: 10.1080/13562510701596315.

Huijser, H., Kimmins, L. and Evans, P. (2008). Peer Assisted Learning in Fleximode:

Developing an Online Learning Community. Australasian Journal of Peer Learning. 1. pp 51-60.

Hull, D. M. and Saxon, T. F. (2009). Negotiation of meaning and co-construction of knowledge: An experimental analysis of asynchronous online instruction. Computers \& Education. 52. pp 624639. doi: 10.1016/j.compedu.2008.11.005.

Ice, P., Curtis, R., Phillips, P. and Wells, J. (2007). Using Asynchronous Audio Feedback to Enhance Teaching Presence and Students' Sense of Community. Journal of Asynchronous Learning Networks. 11(2). pp 3-25.

Irwin, B. and Hramiak, A. (2010). A discourse analysis of trainee teacher identity in online discussion forums. Technology, Pedagogy and Education. 19(3). pp 361-377. doi: 10.1080/1475939x.2010.513767.

Ivanič , R. (1998). Writing and Identity: the discoursal construction of identity in academic writing (e-book). Philadelphia USA, John Benjamins BV.

Kanno, Y. and Stuart, C. (2011). Learning to Become a Second Language Teacher: Identitiesin-Practice. The Modern Language Journal. 95(ii). pp 236-252. doi: 10.1111/j.15404781.2011.01178.x.

Ke, F., Chavez, A. F., Causarano, P.-N. L. and Causarano, A. (2011). Identity Presence and Knowledge Building: Joint Emergence in Online Learning Environments? International Journal of Computer-Supported Collaborative Learning. 6(3). pp 349-370. doi: 10.1007/s11412-011-9114-z.

Kelly, P. and Stevens, C. (2009). Narrowing the Distance: Using E-Learner Support to Enhance the Student Experience. European Journal of Open, Distance and E-Learning, II(2). pp1-6

Kirschner, P. A., Strijbos, J. W., Kreijns, K. and Beers, P. J. (2004). Designing electronic collaborative learning environments. Educational Technology, Research and Development. 52. pp 176.

Koh, M. H. and Hill, J. R. (2009). Student Perceptions of Group Work in an Online Course: Benefits and Challenges. Journal of Distance Education. 23(2). pp 69-92.

Kreijns, K., Kirschner, P. A., Jochems, W. and van Buuren, H. (2004). Measuring perceived quality of social space in distributed learning groups. Computers in Human Behaviour. 20. pp 607-632. doi: 10.1016/j.chb.2003.11.002.

Kwon, K., Han, D., Bang, E. J. and Armstrong, S. (2010). Feelings of isolation and coping mechanism in online learning environments: A case study of asian international students. International Journal of Learning. 17(2). pp 343-356.

Lapadat, J. C. (2007). Discourse Devices used to Establish Community, Increase Coherence, and Negotiate Agreement in an Online University Course. Journal of Distance Education. 21(3). pp 59-92.

Lave, J. and Wenger, E. (1991). Situated Learning: Legitimate Peripheral Participation. Cambridge UK, Cambridge.

Liu, X., Magjuka, R. J., Bonk, C. J. and Lee, S. (2007). Does Sense of Community Matter? An Examination of Participants' Perceptions of Building Learning Communities in Online Courses. Quarterly Review of Distance Education. 8(1). pp 9-22.

Martin, J. R. and White, P. R. R. (2005). The Language of Evaluation: Appraisal in English, NY, Palgrave Macmillan. 
Maslow, A.H. (1968). Toward a psychology of being (2 ${ }^{\text {nd }}$ ed.). New York, Van Nostrand Reinbold

Maurino, P. S. M. (2006). Looking for Critical Thinking in Online Threaded Discussions. EJournal of Instructional Science and Technology. 9(2). 9(2). pp 1-18.

Mercer, N. (2000). Words and Minds: How we use language to think together, London UK, Routledge.

Mercer, N. and Howe, C. (2012). Explaining the dialogic processes of teaching and learning: The value and potential of sociocultural theory. Learning, Culture and Social Interaction. 1(1). pp 12-21. doi: 10.1016/j.lcsi.2012.03.001.

Mitchell, B. and Geva-May, I. (2009). Attitudes Affecting Online Learning Implementation in Higher Education Institutions. Journal of Distance Education. 23(1). pp 71-88.

Moody, J. (2004). Distance Education: Why are the Attrition Rates so High? Quarterly Review of Distance Education. 5(3). pp 205-228.

Moore, M. G. (1993). Theory of transactional distance. In Theoretical Principles of Distance Education. Keegan, D. (Ed.). New York NY, Routledge: pp 22-38.

Muller, T. (2008). Persistence of Women in Online Degree-Completion Programs. International Review of Research in Open and Distance Learning. 9(2). pp 1-18.

Norton, B. (1997). Language, Identity, and the Ownership of English. TESOL Quarterly. 31(3). pp 409-429.

Norton, B. (2000). Identity and Language Learning: Gender, Ethnicity and Educational Change, Essex, England, Pearson Education Limited.

Norton, B. (2010). Identity, Literacy, and English-Language Teaching. TESL Canada Journal. 28(1). pp 1-13.

Olinger, A. R. (2011). Constructing identities through "discourse": Stance and interaction in collaborative college writing. Linguistics and Education. 22(2011). pp 273-286. doi: 10.1016/j.linged.2011.04.001.

Ouzts, K. (2006). Sense of Community in Online Classes. Quarterly Review of Distance Education. 7(3). pp 285-295. doi: 1667401961.

Owens, J., Hardcastle, L. and Richardson, B. (2009). Learning From a Distance: The Experience of Remote Students. Journal of Distance Education. 23(3). pp 53-74.

Pelz, B. (2010). (My) Three Principles of Effective Online Pedagogy. Journal of Asynchronous Learning Networks. 14(1). pp 103-116.

Penuel, W. R. and Wertsch, J. V. (1995). Vygotsky and Identity Formation: A Sociocultural Approach. Educational Psychologist. 30(2). pp 83-92.

Perrotta, C. (2006). Learning to be a psychologist: The construction of identity in an online forum. Journal of Computer Assisted Learning. 22(6). pp 456-466.

Priest, A. (2007). Dialoguing at a distance: How do we communicate with external students? Journal of Academic Language \& Learning. 1(1). pp 113-122.

Richards, K. (2006). 'Being the Teacher': Identity and Classroom Conversation. Applied Linguistics. 27(1). pp 51-77. doi: 10.1093/applin/ami041.

Richardson, J. C. and Ice, P. (2010). Investigating students' level of critical thinking across instructional strategies in online discussions. The Internet and Higher Education. 13(1-2). pp 52-59. doi: 10.1016/j.iheduc.2009.10.009.

Roberts, J. and Crittenden, L. (2009). Accessible Distance Education 101. Research in Higher Education Journal. 4. pp 1-12. 
Rovai, A. P. (2002a). Building Sense of Community at a Distance. International Review of Research in Open and Distance Learning. 3(1). pp 1-16.

Rovai, A. P. (2002b). Development of an instrument to measure classroom community. The Internet and Higher Education. 5(3). pp 197-211.

Rovai, A. P. (2002c). Sense of community, perceived cognitive learning, and persistence in asynchronous learning networks. The Internet and Higher Education. 5(4). pp 319-332. doi: 10.1016/S1096-7516(02)00130-6.

Rovai, A. P., Wighting, M. J. and Liu, J. (2005). SCHOOL CLIMATE: Sense of Classroom and School Communities in Online and On-Campus Higher Education Courses. Quarterly Review of Distance Education. 6(4). pp 361-374.

Rovai, A. P., Wighting, M. J. and Lucking, R. (2004). The Classroom and School Community Inventory: Development, refinement, and validation of a self-report measure for educational research. The Internet and Higher Education. 7(4). pp 263-280. doi: 10.1016/j.iheduc.2004.09.001.

Salmon, G. (2005). Flying not flapping: a strategic framework for e-learning and pedagogical innovation in higher education institutions. Research in Learning Technology. 13(3). pp 201-218. doi: 10.1080/09687760500376439.

Skulstad, A. S. (2005). Competing roles: student teachers using asynchronous forums. International Journal of Applied Linguistics. 15(3). pp 347-363.

Stein, D. S., Wanstreet, C. E., Calvin, J., Overtoom, C. and Wheaton, J. E. (2005). Bridging the Transactional Distance Gap in Online Learning Environments. American Journal of Distance Education. 19(2). pp 105-118. doi: 10.1207/s15389286ajde1902_4.

Swan, K. (2001). Virtual interaction: Design factors affecting student satisfaction and perceived learning in asynchronous online courses. Distance Education. 22(2). pp 306-331.

Tsai, I. C. (2011). Levels and patterns of participation and social interaction in an online learning community for learning to teach. Journal of Interactive Learning Research. 22(2). pp 191-239.

Tudini, V. (2003). Using Native Speakers in Chat. Language Learning \& Technology. 7(3). pp 141-159.

Uzuner, S. (2009). Questions of Culture in Distance Learning: A Research Review. International Review of Research in Open and Distance Learning. 10(3). pp 1-19.

Varghese, M., Morgan, B., Johnston, B. and Johnson, K. A. (2005). Theorizing Language Teacher Identity: Three Perspectives and Beyond. Journal of Language, Identity \& Education. 4(1). pp 21-44. doi: 10.1207/s15327701jlie0401 2.

Vygotsky, L. (1978). Mind in Society: The Development of Higher Psychological Processes, Cambridge Mass, Harvard University Press.

Warschauer, M. (1997). Computer-Mediated Collaborative Learning: Theory and Practice. The Modern Language Journal. 81(4). pp 470-481.

Wenger, E. (1998). Communities of Practice: Learning, Meaning and Identity, Cambridge UK, Cambridge University Press.

White, C. (2003). Language Learning in Distance Education, Cambridge, UK, Cambridge University Press.

Xie, K. and Ke, F. (2011). The role of students' motivation in peer-moderated asynchronous online discussions. British Journal of Educational Technology. 42(6). pp 916-930. doi: 10.1111/j.1467-8535.2010.01140.x. 
Yeh, Y.-C. (2010). Analyzing Online Behaviors, Roles, and Learning Communities via Online Discussions. Educational Technology \& Society. 13(1). pp 140-151.

Yelland, N. and Tsembas, S. (2008). E learning: issues of pedgagogy and practice for the information age. In Learning and the learner: exploring learning for new times. Kell, P., Vialle, W., Konza, D. and Vogl, G. (Eds.). Wollongong, University of Wollongong: 95111. 